Vol 13, Issue 6, 2020

\title{
SELECTIVE TRACE LEVEL DETERMINATION OF 1,4-DIOXANE CONTENT IN SODIUM LAURETH SULFATE RAW MATERIAL BY GAS CHROMATOGRAPHIC-FLAME IONIZATION DETECTION METHOD
}

\author{
LAKSHMI NARASIMHA RAO KATAKAM ${ }^{1 *}$, THIRUPATHI DONGALA ${ }^{2}$ \\ ${ }^{1}$ Department of Analytical Development, Saptalis Pharmaceuticals LLC, Hauppauge, New York 11788, USA. ${ }^{2}$ Department of Analytical \\ Research and Development, Aurex Laboratories LLC, New Jersey 08520, USA. Email: klnrao16@gmail.com
}

Received: 31 January 2020, Revised and Accepted: 12 April 2020

\begin{abstract}
Objective: The study spotlights on a new gas chromatographic (GC) method with flame ionization detection technique that has been developed and validated for the selective determination of 1,4-dioxane content in sodium laureth sulfate (SLS), raw material.

Methods: The method was developed using a Thermo Scientific TR-1 ( $30 \mathrm{~m} \times 0.25 \mathrm{~mm} \times 1.0 \mu \mathrm{m}$ ) column with a carrier gas used as helium. The diluent used as purified water and the flow pressure of the carrier gas is 9.0 psi with a split ratio of 1:5. The optimized method was validated as per the ICH Q2 guidelines.

Results: Regression analysis confers a correlation coefficient for the stated compounds that are found to be greater than 0.999 . The limit of quantitation and limit of detection are established at a sensitive determination level of 9 ppm and 3 ppm, respectively.

Conclusion: The validated and rugged GC method developed for the determination of 1,4-dioxane using a specific GC method in the SLS raw material. The recovery results prove the sound judgment in the determination of accuracy toward its evaluation. Hence, the validated analytical method was specific, selective, economical, and accurate for the determination of 1,4-dioxane by gas chromatographic method with flame ionization detection technique.
\end{abstract}

Keywords: 1,4-Dioxane, Sodium laureth sulfate, Raw material, Gas chromatographic with flame ionization detection, Trace level determination.

(C) 2020 The Authors. Published by Innovare Academic Sciences Pvt Ltd. This is an open access article under the CC BY license (http://creativecommons. org/licenses/by/4. 0/) DOI: http://dx.doi.org/10.22159/ajpcr.2020.v13i6.37435

\section{INTRODUCTION}

The appearance of sodium laureth sulfate (SLS/SDS) raw material has the Flowable paste/powder and transparent to yellowish color. SLS is the key material for the manufacture of liquid dishwashing and technical agents as well as liquid light duty-detergents. Because of its excellent foam characteristic and the natural thickening with salt, the product is also suited as a primary surfactant for cosmetic cleansing preparation such as shampoo, shower gel, and foam baths. Sodium lauryl ether sulfate derived from natural fatty alcohols.

The purification process of the SLS raw material eliminates most of the components, namely, sodium chloride, sodium sulfate, and 1,4-dioxane and unsulfated alcohol. However, the quantitation levels shall be determined using the selective analytical methodology for 1,4-dioxane impurity. The literature describes few methods on the determination of 1,4-dioxane using specific variable instrumentation techniques such as gas chromatographic (GC) with flame ionization detection (FID), GC with mass detection on a variety of raw materials, namely, fatty oil alcohols [1,2], polysorbates [3], ethoxylated surfactants [4-6], and few of them were reported in finished product cosmetic applications [7-11]. There were several other kinds of literature sourced as the major contaminant in water $[12,13]$ and listed as environmentally hazardous [14] and possible risk assessments in terms of carcinogenicity [15] and household detergent and personal care products [16] were also reported. No instrumental analysis was reported for 1,4-dioxane determination and none of the methods found relevant either in the similar sample matrix. Hence, a method was developed and validated to determine the 1,4-dioxane (as a contaminant impurity) by gas chromatography with flame ionization technique to evaluate the quality and purity of the SLS, raw material.

\section{EXPERIMENTAL}

Chemicals and types of equipment

The purity of 1,4-dioxane used as analytical grade (>95\%) in chromatographic development. Purified water prepared using a Milli-Q Plus water purification system (Millipore, Milford, MA, USA). GC column

Table 1: Gas chromatograph and headspace conditions

\begin{tabular}{|c|c|c|c|c|}
\hline \multicolumn{5}{|c|}{ GC oven conditions } \\
\hline \multicolumn{2}{|c|}{$\begin{array}{l}\text { Initial temperature } \\
: 70.0^{\circ} \mathrm{C}\end{array}$} & \multicolumn{3}{|c|}{ Initial time: $0.0 \mathrm{~min}$} \\
\hline Ramp\# & $\begin{array}{l}\text { Rate } \\
\left({ }^{\circ} \mathrm{C} / \mathrm{min}\right)\end{array}$ & $\begin{array}{l}\text { Final } \\
\text { temperature }\left({ }^{\circ} \mathrm{C}\right)\end{array}$ & $\begin{array}{l}\text { Hold time } \\
\text { (min) }\end{array}$ & $\begin{array}{l}\text { Total time } \\
\text { (min) }\end{array}$ \\
\hline 1 & 12.0 & 190 & 0.00 & 10.00 \\
\hline 2 & 30.0 & 220 & 19.00 & 30.00 \\
\hline \multicolumn{5}{|c|}{ Run time : $30.00 \mathrm{~min}$} \\
\hline \multicolumn{5}{|c|}{ Oven equilibration time: $0.00 \mathrm{~min}$} \\
\hline \multicolumn{5}{|c|}{ Headspace autosampler conditions } \\
\hline \multicolumn{3}{|c|}{ Oven temperature } & \multicolumn{2}{|l|}{$90^{\circ} \mathrm{C}$} \\
\hline \multicolumn{3}{|c|}{ Loop temperature } & \multicolumn{2}{|l|}{$120^{\circ} \mathrm{C}$} \\
\hline \multicolumn{3}{|c|}{ Transfer line temperature } & \multicolumn{2}{|l|}{$130^{\circ} \mathrm{C}$} \\
\hline \multicolumn{3}{|c|}{ GC cycle time } & \multicolumn{2}{|l|}{$60 \mathrm{~min}$} \\
\hline \multicolumn{3}{|c|}{ Vial equilibration time } & \multicolumn{2}{|l|}{$30.0 \mathrm{~min}$} \\
\hline \multicolumn{3}{|c|}{ Fill mode } & \multicolumn{2}{|c|}{ Fill at flow to pressure } \\
\hline \multicolumn{3}{|c|}{ Fill pressure } & \multicolumn{2}{|l|}{$15 \mathrm{psi}$} \\
\hline \multicolumn{3}{|l|}{ Fill flow } & \multicolumn{2}{|l|}{$50 \mathrm{~mL} / \mathrm{min}$} \\
\hline \multicolumn{3}{|c|}{ Loop volume } & \multicolumn{2}{|l|}{$1 \mathrm{~mL}$} \\
\hline \multicolumn{3}{|c|}{ Pressure equilibration } & \multicolumn{2}{|l|}{$3.00 \mathrm{~min}$} \\
\hline \multicolumn{3}{|c|}{ Vial shake mode } & \\
\hline \multicolumn{3}{|c|}{ Inject time } & \multicolumn{2}{|l|}{$0.3 \mathrm{~min}$} \\
\hline
\end{tabular}


obtained from Thermo Fisher Scientific Inc., USA. The chromatography technique developed in Agilent Gas Chromatograph (model 6890N) with headspace sampler (7697A) and FID equipped with waters empower software.

\section{Chromatographic conditions}

The method was developed using a Thermo Scientific TR-1 $(30 \mathrm{~m} \times 0.25 \mathrm{~mm} \times 1.0 \mu \mathrm{m})$ column with a carrier gas used as helium. The diluent used as purified water and the flow pressure of the carrier gas is 9.0 psi with a split ratio of $1: 5$. The inlet and detector temperatures are maintained at $130^{\circ} \mathrm{C}$ and $300^{\circ} \mathrm{C}$, respectively. The fuel and oxidizer flow rates maintained at 1:10 with a constant makeup gas of nitrogen with a flow rate of 25 $\mathrm{mL} / \mathrm{min}$ operated with FID. The total chromatographic run time of 25 min. The gas chromatograph column oven conditions and headspace conditions are presented in Table 1.

\section{Working standard preparation}

Accurately weigh about $300 \mathrm{mg}$ of 1,4-dioxane standard into respective $100 \mathrm{~mL}$ volumetric flask contained $20 \mathrm{~mL}$ of purified water. Dilute to volume with purified water and mix well. Pipette $10.0 \mathrm{~mL}$ of stock standard solution into $100 \mathrm{~mL}$ volumetric flask and dilute to volume with purified water and mix well. Pipette $2.0 \mathrm{~mL}$ of above solution into $100 \mathrm{~mL}$ volumetric flask and dilute to volume with purified water and mix well. Transfer $5.0 \mathrm{~mL}$ of intermediate stock standard preparation into $20 \mathrm{~mL}$ headspace vial and seal the vial for analysis. The concentration of 1,4-dioxane is equivalent to $30 \mathrm{ppm}$ with respect to sample concentration. The system suitability of the chromatographic analysis is presented in Table 2 . The representative chromatograms of the blank and working standard preparation are shown in Figs. 1 and 2.

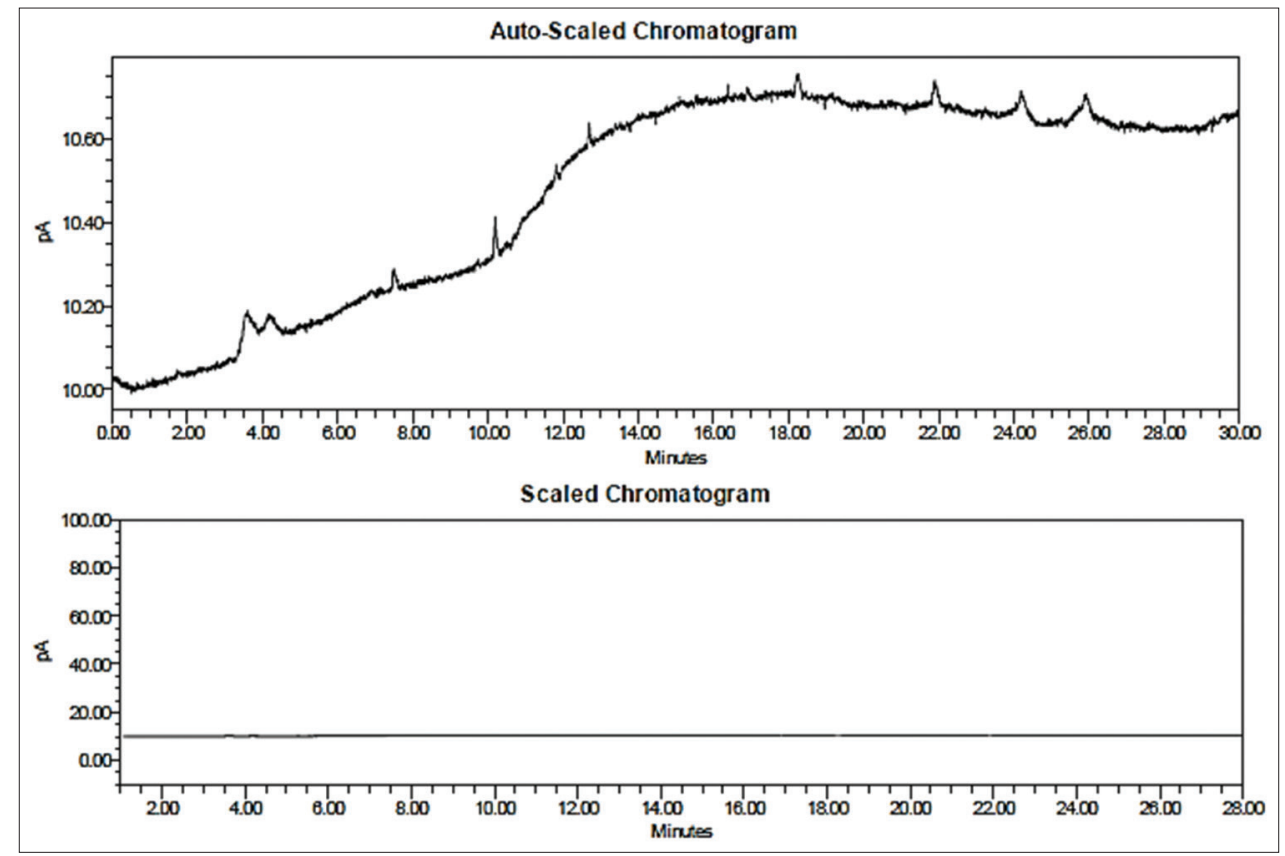

Fig. 1: Blank chromatogram

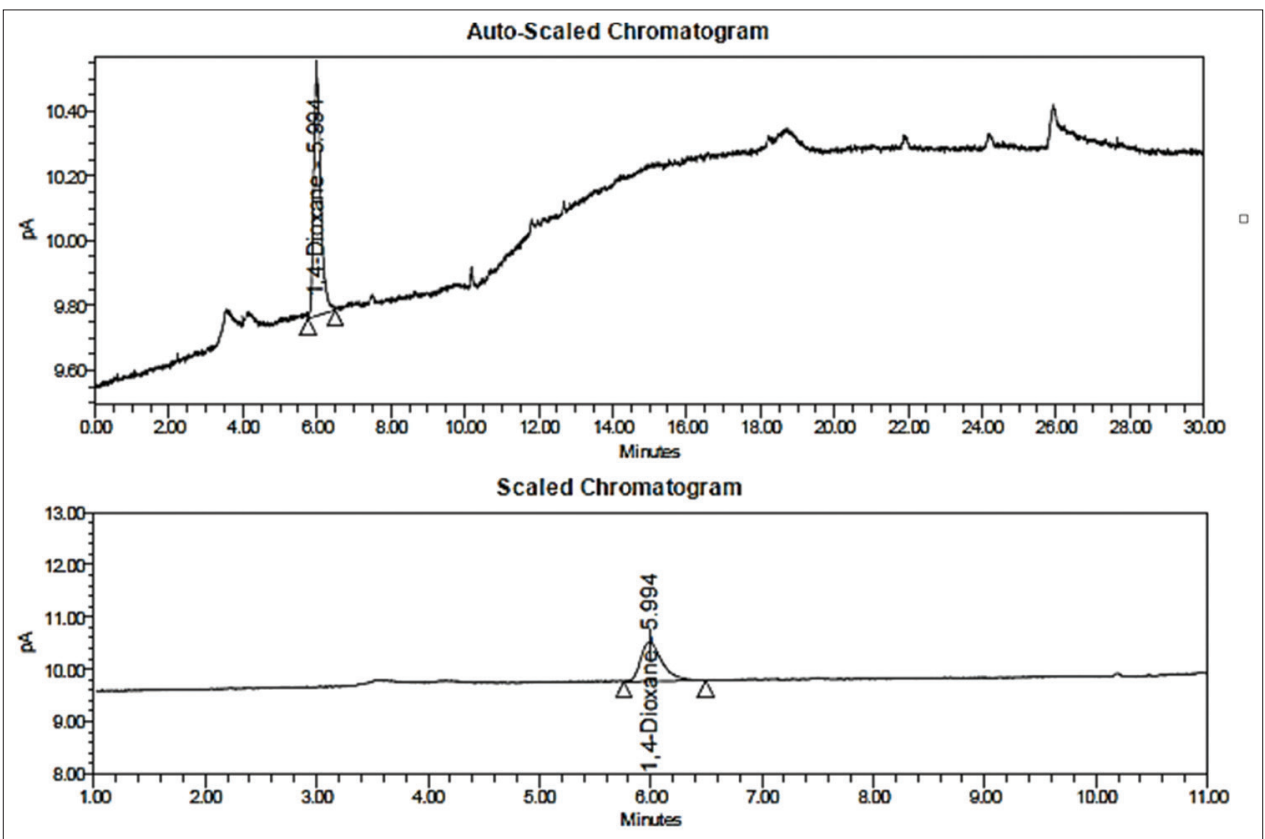

Fig. 2: Working standard chromatogram 


\section{Sample preparation}

Accurately weigh about $1.0 \mathrm{~g}$ of SLS raw material into $20 \mathrm{~mL}$ headspace vial, add $5.0 \mathrm{~mL}$ of purified water to the headspace vial and seal the vial for analysis. The chromatogram of the control sample is shown in Fig. 3.

\section{RESULTS AND DISCUSSION}

The proposed method validated as per the ICH guidelines [17] and USP Compendia [18] along with the references literature on method validation [19-28] studies in current industry practices.

\section{Method precision}

Method precision/repeatability was determined for SLS raw material by analyzing six sample preparations of raw material spiked with 1,4-dioxane at specification level (30 ppm). A control sample was prepared to correct the recovery with a known amount of 1,4-dioxane detected in the control sample. The results for method precision are presented in Table 3. The representative chromatogram of the control sample and spiked sample (at specification $30 \mathrm{ppm}$ ) is presented in Figs. 3 and 4.

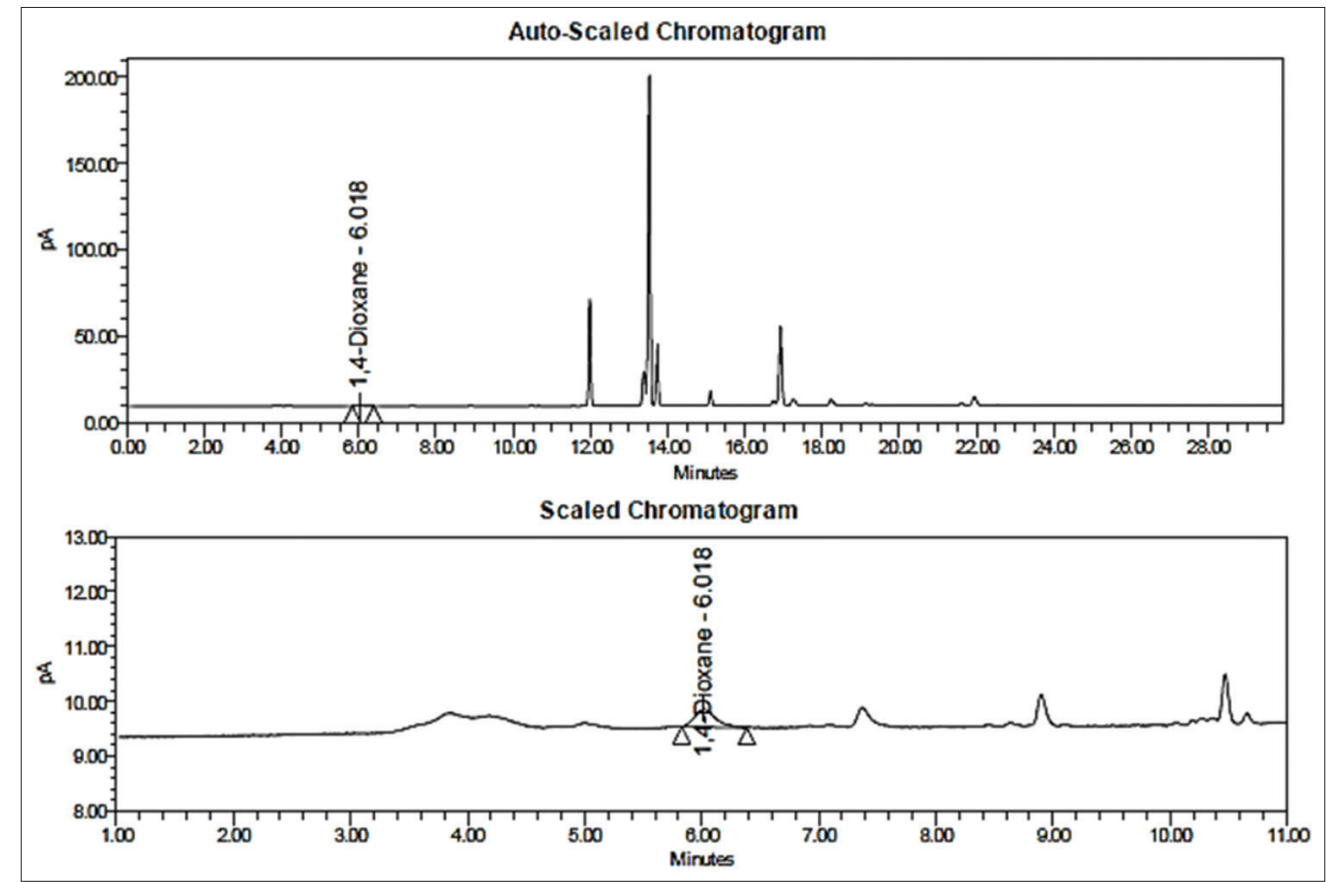

Fig. 3: Control sample chromatogram

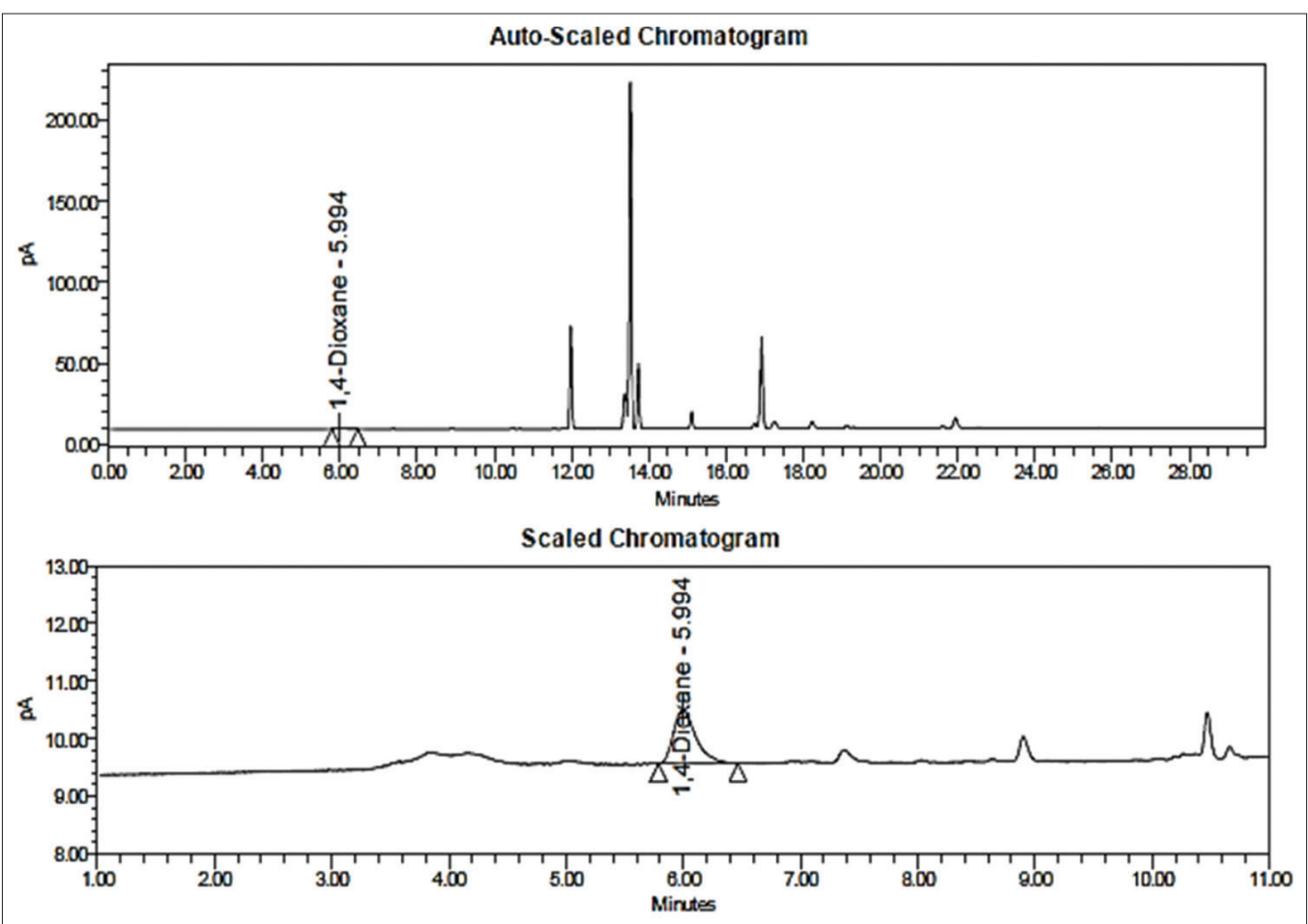

Fig. 4: Spiked sample chromatogram 


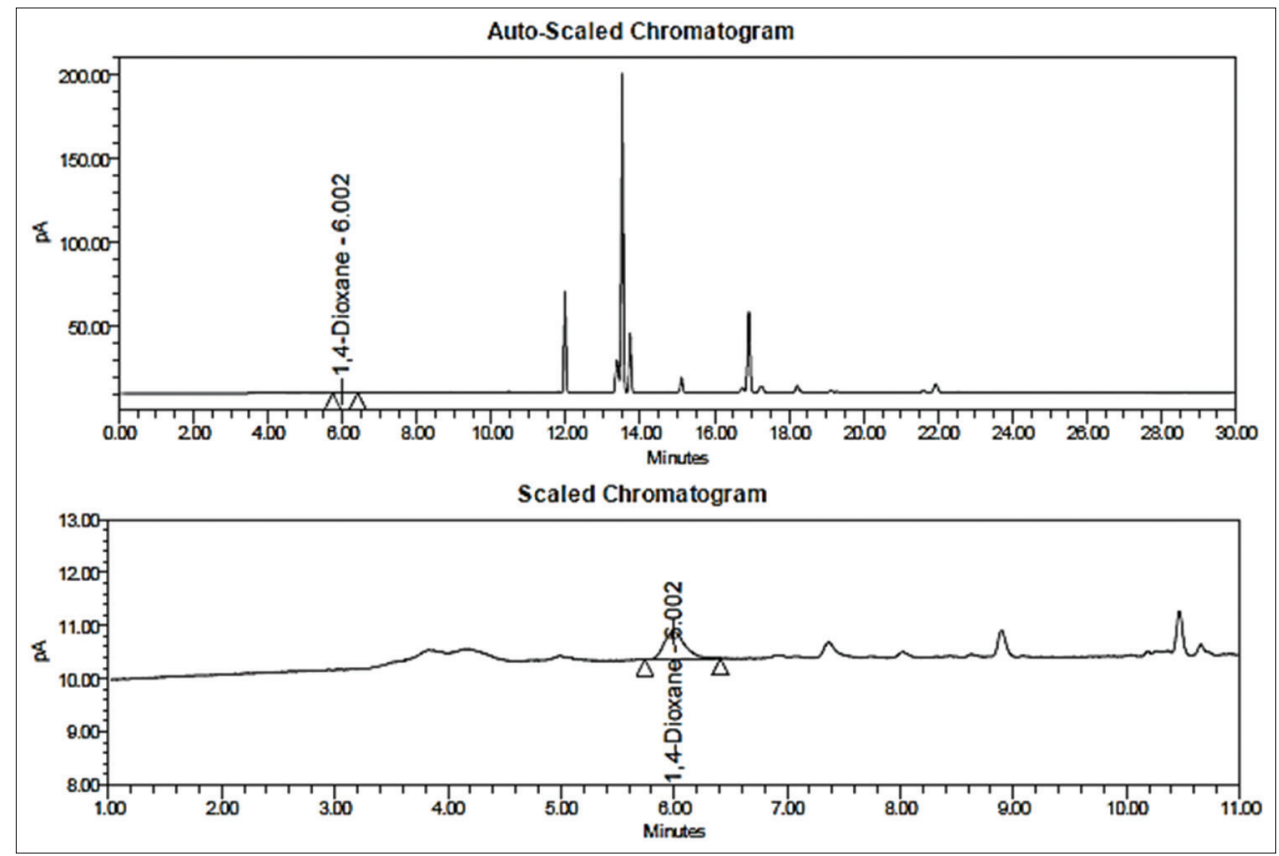

Fig. 5: Limit of quantitation chromatogram

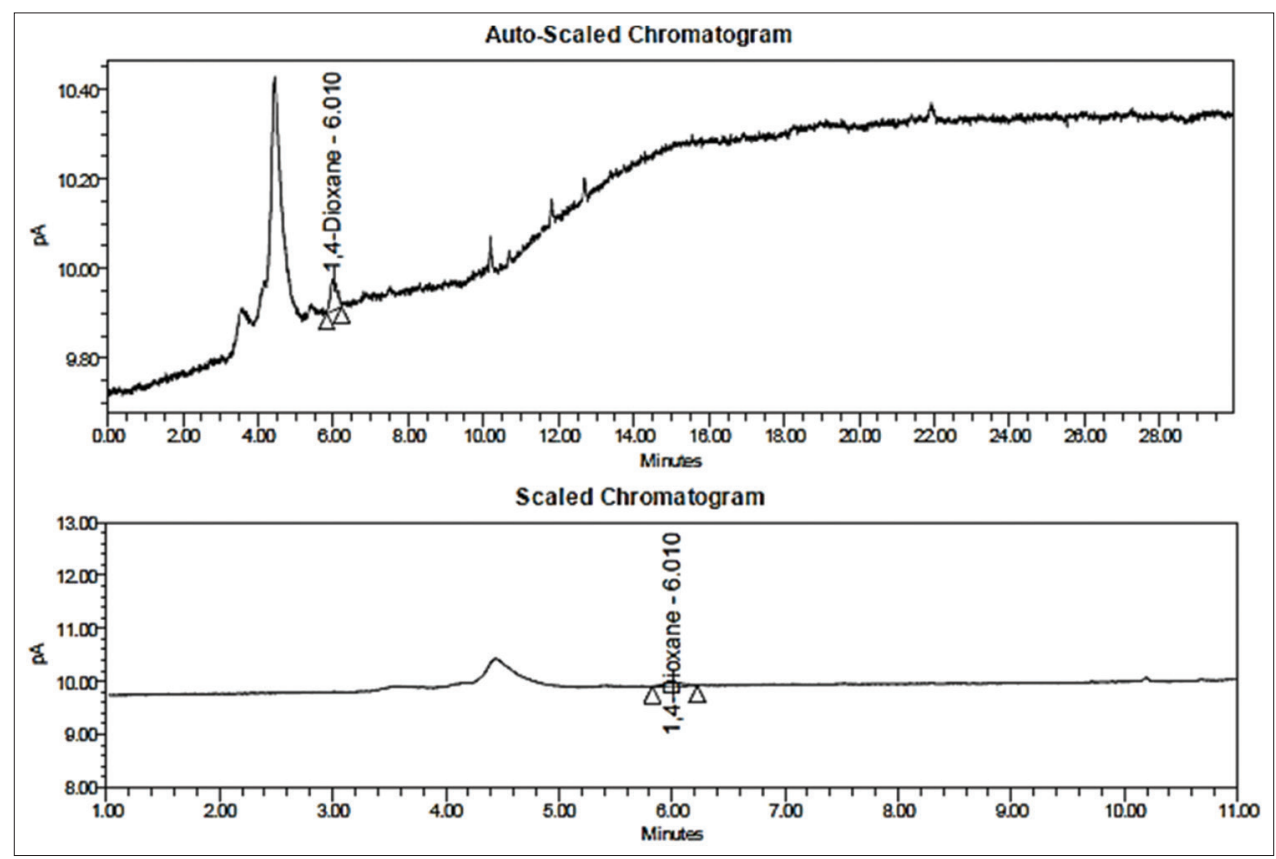

Fig. 6: Limits of detection chromatogram

Table 2: System suitability information

\begin{tabular}{lllll}
\hline Component & $\begin{array}{l}\text { Retention } \\
\text { time (min) }\end{array}$ & $\begin{array}{l}\text { Relative } \\
\text { retention time }\end{array}$ & $\begin{array}{l}\text { System suitability } \\
\text { criteria }\end{array}$ \\
\cline { 3 - 5 } & & $\begin{array}{l}\text { USP } \\
\text { tailing }\end{array}$ & $\%$ RSD $^{\dagger}$ \\
\hline 1,4-Dioxane & 1.7 & 0.06 & NMT 1.5 & NMT 10.0 $^{+}$ \\
\hline
\end{tabular}

${ }^{\dagger}$ For six replicate standard injections

Specificity

The specificity of the method was demonstrated by injecting blank, working standard, control, and spiked sample at specification level
Table 3: Method precision and accuracy evaluation

\begin{tabular}{lll}
\hline \multirow{2}{*}{ \% Level } & \multicolumn{1}{l}{ 1,4-dioxane - \% recovery } \\
\cline { 2 - 3 } & Average & \% RSD $^{\dagger}$ \\
\hline Limit of quantitation $(\sim 9 \mathrm{ppm})$ & 100.2 & 15.7 \\
$100 \%(\sim 30 \mathrm{ppm})$ & 84.9 & 1.8 \\
$125 \%(\sim 37.5 \mathrm{ppm})$ & 100.5 & 3.0 \\
\hline${ }^{\dagger}$ Determined on multiple sample preparations
\end{tabular}

(30 ppm). No significant interference was observed at the retention time of 1,4-dioxane from diluent. The results for specificity are presented in Table 3 and representative chromatograms are presented in Figs. 1-4. 


\section{Accuracy}

The accuracy was determined by spiking known concentrations of 1,4-dioxane in triplicate preparations at limit of quantitation (LOQ) and $125 \%$ level, and six sample preparations at a $100 \%$ level with respect to specification limit. A control (un-spiked) sample was prepared to correct the \% recovery with a known amount of 1,4-dioxane detected in the control sample. The amount of 1,4-dioxane detected in the control sample was $0.012 \mu \mathrm{g} / \mathrm{mL}$. The obtained recoveries are presented in Table 3 .

\section{Limits of detection (LOD) and LOQ}

LOQ was established by making serial dilutions of standard solution to obtain a concentration of about $9 \mu \mathrm{g} / \mathrm{mL}$. Representative chromatograms of the LOQ and LOD solutions are presented in Figs. 5 and 6.

\section{Linearity}

The linearity of the method was demonstrated by injecting series of standard solutions of 1,4-dioxane at five different concentration levels ranging from LOQ $9 \mathrm{ppm}$ to $50 \mathrm{ppm}$-level. The correlation coefficient for 1,4-dioxane found to be 0.9992 .

\section{Stability of mobile phase and solutions}

The solution stability was established for working standard and control sample solution which are found to be stable for $72 \mathrm{~h}$ at room temperature condition.

\section{CONCLUSION}

The validated and rugged GC method developed for the determination of 1,4-dioxane using a specific GC method in the SLS raw material. The recovery results prove the sound judgment in the determination of accuracy toward its evaluation. Hence, the validated analytical method was specific, selective, economical, and accurate for the determination of 1,4-dioxane by GC method with FID technique.

\section{ACKNOWLEDGMENTS}

The author expresses his gratitude to the Saptalis Pharmaceuticals LLC and Aurex Laboratories LLC for providing laboratory facility for this research work.

\section{AUTHOR'S CONTRIBUTIONS}

The author has solely contributed in the design, development, review, and finalization of the contents of the manuscript.

\section{CONFLICTS OF INTEREST}

The author confirms that this article content has no conflicts of interest.

\section{AUTHOR'S FUNDING}

No funding was provided for this research.

\section{REFERENCES}

1. Tay BY, Maurad Z, Muhammad H. Gas chromatography with flame ionization detection of 1,4-dioxane in palm-based fatty alcohol ethoxylates. J Am Oil Chem Soc 2014;91:1103-10.

2. Scalia S. Reversed-phase high-performance liquid chromatographic method for the assay of 1,4-dioxane in sulphatedpolyoxyethylene alcohol surfactants. J Pharm Biomed Anal 1990;8:867-70.

3. Birkel TJ, Warner CR, Fazio T. Gas chromatographic determination of 1,4-dioxane in polysorbate 60 and polysorbate 80 . J Assoc Off Anal Chem 1979;62:931-6.

4. Robinson JJ, Ciurxczak EW. Direct gas chromatographic determination of 1,4-dioxane in ethoxylated surfactants. J Soc CosmetChem 1980;31:329-37.

5. Stafford ML, Guin KF, Johnson GA, Sanders LA, Rockey SL. Analysis of 1,4-dioxane in ethoxylated surfactants. J Soc CosmetChem 1980;31:281-7.

6. Waldman BA. Analysis of 1,4-dioxane in ethoxylated compounds by gas chromatography/mass spectrometry using selected ion monitoring.
J Soc CosmetChem 1982;33:19-25.

7. Fuh CB, Lai M, Tsai HY, Chang CM. Impurity analysis of 1,4-dioxane in nonionic surfactants and cosmetics using headspace solidphase microextraction coupled with gas chromatography and gas chromatography-mass spectrometry. J Chromatogr A 2005;1071:141-5.

8. Guo W, Brodowsky H. Determination of the trace 1,4-dioxane. Microchem J 2000;64:173-9.

9. Black RE, Hurley FJ, Havery DC. Occurrence of 1,4-dioxane in cosmetic raw materials and finished cosmetic products. J AOAC Int 2001;84:666-70.

10. Zhou W. The determination of 1,4-dioxane in cosmetic products by gas chromatography with tandem mass spectrometry. J Chromatogr A 2019;1607:460400.

11. TaharaM, ObamaT, IkarashiY. Development of analytical method for determination of 1,4-dioxane in cleansing products. Int J CosmetSci 2013;35:575-80.

12. Xiyan X, Liu S, Smith K, Wang Y,Hu H. Light-driven breakdown of 1,4-dioxane for potable reuse: A review. ChemEngJ 2019;373:508-18.

13. Pollitt KJ, Kim J, Peccia J, Elimelech M, Zhang Y, CharkoftakiG, et al. 1,4-dioxane as an emerging water contaminant: State of the science and evaluation of research needs. Sci Total Environ 2019;690:853-66.

14. USEnvironmentalProtectionAgency. 1,4-Dioxane(1,4-Diethyleneoxide). Hazard Summary-Created; 1992.Available from: http://www.epa.gov/ $\mathrm{ttn} / \mathrm{atw} / \mathrm{hlthef} /$ dioxane.html. [Last accessed on2020 Jan].

15. National Cancer Institute.Bioassay of 1,4-Dioxane for Possible Carcinogenicity. CAS No. 123-91-1. NCI Carcinogenesis Technical Report Series No. 80. NCI-CG-TR80. Bethesda: National Institutes of Health; 1978.

16. Matheson L, Russell G, MacArthur B,Sheats WB. 1,4-Dioxane-A Current Topic for Household Detergent and Personal Care Formulators $100^{\text {th }}$ AOCS Annual Meeting. Oral Presentation. Available from: http:// www.sasoltechdata.com/marketingbrochures/14dioxane.pdf.

17. ICH and Q2B.Harmonized Tripartite Guideline, Validation of Analytical Procedure: Methodology, IFPMA, in Proceedings of the International Conference on Harmonization; 1996.

18. Pappa HN. Validation of compendialprocedures.USP Pharmacopeial Forum 2019;42:8046-52.

19. Rao KL, Aboul-Enein HY. Elemental impurities determination by ICPAES/ICP-MS: A review of theory, interpretation of concentration limits, analytical method development challenges and validation criterion for pharmaceutical dosage forms.Curr Pharm Anal 2019;16:1-12.

20. Rao KL, Reddy KP. Development and validation of a stability-indicating LC method for simultaneous determination of related compounds of guaifenesin, terbutaline sulfate and ambroxolHCl in cough syrup formulation. J Saudi ChemSoc 2014;18:593-600.

21. Rao KL, Reddy KP. Stability-Indicating method for simultaneous determination of polar and non-polar related compounds of zidovudinein drug substance and drug product tablet form. Int J Res PharmSci 2015;6:5-14

22. Dongala T, Katakam LN,PalakurthiAK, Katari NK. RP-HPLC stability indicating method development and validation of pseudoephedrine sulfate and related organic impurities in tablet dosage forms, robustness by QbDapproach. AnalChemLett 2019;9:697-710.

23. Pathan M, Kshirsagar A. Development of validated stability indicating method by RP-HPLC for simultaneous estimation of meropenemand vaborbactamin bulk and pharmaceutical formulation. Int $\mathrm{J}$ PharmPharmSci 2019;11:102-8.

24. Jamal MK, GazyAA. Development and validation of analytical spectrophotometric and RP-HPLC methods for the simultaneous estimation of hydroquinone, hydrocortisone and tretinointernary mixture in topical formulation. Int J PharmPharmSci2019;11:10-6.

25. Rao KL. Split-half tablets: A complete review for analytical testing. Asian J Pharm Clin Res 2019;12:27-38

26. Rao KL, Rao KP. Development and validation of a stability-indicating LC method for determination of bexarotene in softgel dosage formulation.Chromatographia 2017;80:1211-24.

27. Rao KL, Reddy KP. Stability-indicating liquid chromatographic method for the simultaneous determination of ascorbic acid, citric acid, butylatedhydroxyanisole, simvastatin and related compounds in pharmaceutical solid dosage form. Int $\mathrm{J}$ Anal Pharm Biomed Sci2014;3:1-10

28. Rao KL, Reddy KP. Simultaneous estimation of fluticasone propionate, azelastine hydrochloride, phenylethyl alcohol and benzalkonium chloride by RP-HPLC method in nasal spray preparations. Int J Res PharmSci2010;1:473-80. 